\title{
Peripheral T-Cell Lymphoma Mimicking Marginal Zone B-Cell Lymphoma
}

Patricia Uherova, M.D., Charles W. Ross, M.D., William G. Finn, M.D., Timothy P. Singleton, M.D., Rina Kansal, M.D., Bertram Schnitzer, M.D.

Department of Pathology, University of Michigan Medical School, Ann Arbor, Michigan

Peripheral T-cell lymphoma (PTCL) may assume a variety of histologic and cytologic appearances. We describe eight cases of PTCL morphologically simulating marginal zone B-cell lymphoma. We reviewed PTCL cases diagnosed in our institution between 1990 and 2000 and selected eight cases for study based on the following criteria: small-cell morphology with abundant, clear cytoplasm and either marginal zone involvement by the neoplastic infiltrate in lymph node biopsies or lymphoepithelial lesions in extranodal biopsies. Histologic features and ancillary studies were reviewed. Patients included six women and two men with a median age of 53 years (range, 35 to 74 years). Six patients were diagnosed with primary nodal PTCL, and two presented with primary extranodal disease. The original diagnosis was PTCL in only four cases; three cases were diagnosed as atypical lymphoid infiltrate, and one case as benign lymphoepithelial lesion. Lymph node biopsies revealed partial effacement of the architecture with residual follicles surrounded by the neoplastic small cells. Extranodal sites included hard palate, tongue, tonsil, and submandibular glands; all but one case demonstrated lymphoepithelial lesions. Monoclonality was demonstrated in six of eight cases (rearrangement of T-cell receptor gene), and three of eight had an aberrant $T$-cell population by flow cytometry. The differential diagnosis of atypical lymphoid infiltrates with morphologic features of marginal zone B-cell lymphoma should include PTCL. This uncommon morphological mimicry should be recognized, because PTCL is an aggressive disease regardless of morphology and should be treated accordingly.

Copyright (C) 2002 by The United States and Canadian Academy of Pathology, Inc

VOL. 15, NO. 4, P. 420, 2002 Printed in the U.S.A.

Date of acceptance: December 20, 2001.

Address reprint requests to: Bertram Schnitzer, M.D., University of Michigan, Room M5242 Medical Science I, 1301 Catherine, Ann Arbor, MI 48109-0602; fax: (734) 936 2756; e-mail: raven@umich.edu.
KEY WORDS: Marginal zone B-cell lymphoma, Peripheral T-cell lymphoma.

Mod Pathol 2002;15(4):420-425

Peripheral T-cell lymphomas (PTCL) are relatively rare, comprising only approximately $15 \%$ of nonHodgkin's lymphomas in the United States. They are associated with an aggressive clinical course. Median survival ranges from 10 to 30 months, comparable to that of other diffuse aggressive lymphomas (1). Classification of these neoplasms has been controversial. Previous schemes such as Rappaport's, the Working Formulation, or the updated Kiel classification have been based mainly on cytological features (2-4). However, the cytological features in PTCL correlated poorly with disease entities, and there were no reliable criteria to subclassify these tumors (5). The Revised European-American Classification of Lymphoid Neoplasms as well as the new World Health Organization Classification subdivided peripheral $\mathrm{T}$ - and natural killer (NK)-cell neoplasms according to the anatomic site of involvement and the clinical syndromes $(6,7)$. By definition, peripheral T-cell lymphoma, unspecified, is a heterogeneous and somewhat ill-defined category. In fact, it is a diagnosis of exclusion for predominantly nodal T-cell neoplasms that cannot be defined as a distinct clinicopathological entity, such as angioimmunoblastic T-cell lymphoma, anaplastic large cell lymphoma, or adult T-cell leukemia and lymphoma.

Morphologically, PTCL may assume a variety of histologic and cytological appearances and cannot be easily characterized (8). The neoplastic T-cell infiltrate is predominantly diffuse, first involving the paracortical T-zone and later replacing the entire cortex of the lymph node. The presence of an inflammatory background including eosinophils, plasma cells, and histiocytes is common. The malignant lymphoid population represents a spectrum from small to large to anaplastic cells. Nuclear pleomorphism with prominent nuclear irregularity and lobulation is often seen in both small and large lymphoid cells. 
Rare cases contain a uniform small lymphocytic population with round nuclei and a moderate amount of pale or clear cytoplasm (8). If combined with architectural features unusual for T-cell neoplasms, these cases might be misinterpreted as lowgrade B-cell lymphomas or as atypical lymphoid proliferation on conventional hematoxylin and eosin-stained sections. In this study, we describe eight cases of PTCL that morphologically mimic marginal zone B-cell lymphoma.

\section{MATERIALS AND METHODS}

\section{Patients}

We reviewed PTCL cases diagnosed in our institution between 1990 and 2000. Eight cases were selected based on the following criteria: monomorphous neoplastic population consisting of small cells with abundant, clear cytoplasm and either marginal zone involvement by the neoplastic infiltrate in lymph node biopsies or lymphoepithelial lesions in extranodal biopsies. Histologic features and ancillary studies were reviewed.

\section{Light Microscopy}

Tissue was fixed with $10 \%$ formalin and/or B5 fixative and processed routinely for paraffin embedding. Sections of paraffin-embedded tissue (3-5 $\mu \mathrm{m}$ thick) were stained with hematoxylin and eosin. Confirmatory immunohistochemical stains were performed using an automated method as follows. Tissue sections were deparaffinized, pretreated before immunostaining depending on the specific antibody, and stained on the Ventana ES automated stainer using the ABC method (Ventana Medical Systems, Inc., Tucson, AZ). All reagents placed on the Ventana instrument were purchased from Ventana, except for primary antibodies. The following panel of primary antibodies was used: CD3 (Leu4; DAKO, Copenhagen, Denmark), CD20 (L26; DAKO, Copenhagen, Denmark), CD43 (Leu22; Becton Dickinson, Mountain View, CA), CD45 (CLA; DAKO, Copenhagen, Denmark), CD79a (DAKO, Copenhagen, Denmark). CD30 (BerH2; DAKO, Copenhagen, Denmark) and CD56 (NCAM; Accurate Chemical \& Scientific Corporation, Westbury, NY) staining was performed in six of eight cases and ALK-1 (DAKO, Copenhagen, Denmark), in four of eight cases. Lesions were considered to be of $\mathrm{T}$-cell origin if they expressed CD45, CD3, and CD43 but lacked B-cell-associated and NK-cellassociated markers. An anti-cytokeratin cocktail (AE1/AE3; Roche Diagnostics, Indianapolis, IN, and CAM5.2; Becton-Dickinson, Mountain View, CA) was used in extranodal biopsies to highlight lymphoepithelial lesions.

\section{Flow Cytometry}

Flow-cytometric immunophenotyping was performed by four-color immunofluorescence staining. Cell suspensions obtained from lymph nodes or extranodal soft tissues were incubated with antibody cocktails according to the manufacturer's recommendation. Samples were analyzed using an EPICS XL-MCL flow cytometer (Beckman-Coulter, Miami, FL). Surface membrane immunophenotyping of lymphoma cells was performed using a panel of monoclonal antibodies including anti-CD2, CD3, CD4, CD5, CD7, CD8, CD10, CD11c, CD14, CD19, CD20, CD22, CD23, CD45, FMC7, and kappa and lambda immunoglobulin light chain.

\section{T-Cell Receptor and Immunoglobulin Gene Rearrangement Studies}

The DNA used for gene rearrangement studies was extracted from frozen tissue specimens (lymph nodes or mucosa) using standard phenolchloroform extractions or Puregene DNA Isolation Kit (Gentra Systems, Minneapolis, MN). Purified DNA in the amount of $10 \mu \mathrm{g}$ was digested with the following restriction enzymes: BamH1, EcoR1, and HindIII (Bethesda Research Laboratory, Bethesda, MD) for the T-cell receptor gene; BglII, BamHI/ HindIII (Bethesda Research Laboratory, Bethesda, MD) for the immunoglobulin heavy chain gene; and BglII and HindIII (Bethesda Research Laboratory, Bethesda, MD) for the kappa immunoglobulin light chain gene. After digestion, the DNA was size fractionated by agarose gel electrophoresis $(0.7 \%)$ and transferred from the gel to a nylon membrane (Biodyne B membrane; Gibco/BRL, Gaithersburg, MD) by the Southern transfer technique. Filters were hybridized with ${ }^{32} \mathrm{P}$-labeled DNA probes for the T-cell receptor $\beta$-chain gene (JBeta I/JBeta II; Oncor, Gaithersburg, MD) or immunoglobulin heavy and light chain genes $\mathrm{J}_{\mathrm{H}}$ and $\mathrm{J}_{\mathrm{K}}$; Oncor, Gaithersburg, MD) followed by autoradiography. In Case 4, DNA was hybridized with FITC-labeled probes using the DAKO Chemiluminescent System for nucleic acid blotting (DAKO, Carpinteria, CA) followed by chemiluminescent detection.

\section{RESULTS}

\section{Clinicopathologic Data}

Patients included 6 women and 2 men with a median age of 53 years (ranging from 35 to 74 years, with age not available in 1 case). Six patients presented with primary nodal PTCL, and two presented with primary extranodal disease. An original diagnosis of PTCL was made in only four cases, with three cases diagnosed as atypical lymphoid infiltrate and one case as benign lymphoepithelial le- 


\begin{tabular}{ccll}
\hline No. & Age $(\mathrm{y}) /$ Sex & \multicolumn{1}{c}{ Original Diagnosis } & Biopsy Site \\
\hline 1 & $53 / \mathrm{F}$ & Peripheral T-cell lymphoma & LN-C \\
2 & $59 / \mathrm{F}$ & Peripheral T-cell lymphoma & LN-C, submandibular gland \\
3 & $46 / \mathrm{F}$ & Angioimmunoblastic lymphoma & LN-B, tonsil \\
4 & $46 / \mathrm{M}$ & Benign lymphoepithelial lesion & Hard palate \\
5 & $35 / \mathrm{F}$ & Peripheral T-cell lymphoma & Tongue \\
6 & $56 / \mathrm{M}$ & Atypical lymphoproliferative process & LN-A \\
7 & NA/F & Atypical lymphoproliferative process & LN-C \\
8 & $74 / \mathrm{F}$ & Atypical lymphoid infiltrate, favor reactive & \\
\hline
\end{tabular}

LN-C, cervical lymph node; LN-I, inguinal lymph node; LN-A, axillary lymph node; LN-B, bile duct lymph node.

${ }^{\text {a }}$ original diagnosis not reviewed at our institution.

sion (see Table 1). A total of six lymph nodes and four extranodal biopsies were available for review. Two patients with primary nodal disease (Patients 2 and 3) had biopsy-proven extranodal involvement by PTCL.

\section{Histologic and Immunohistochemical Characteristics}

Histologic features are summarized in Tables 2 and 3. Five of six lymph node biopsies revealed partial effacement of the architecture, with residual follicles and compressed germinal centers surrounded by neoplastic small T-cells (Fig. 1A-B). Significant expansion of the marginal zone, in a pattern similar to marginal zone B-cell lymphoma, was noted in 3 cases (Fig. 1C). In other cases, the neoplastic infiltrate extended into the paracortical zone in a diffuse or vaguely nodular pattern. Obliteration of subcapsular sinuses by the T-cell population, resembling monocytoid B cells, was noted in two cases. Extranodal biopsies included hard palate, tongue, tonsil, and submandibular glands, all but one demonstrating lymphoepithelial lesions similar to those of MALT lymphoma (Fig. 2A-D). Infiltrates of eosinophils characteristic of PTCL were noted in only two biopsies. Proliferation of high endothelial venules was seen in one lymph node biopsy and was associated with diffuse effacement of the architecture.
At high magnification, the neoplastic infiltrate was composed of uniform small-to-intermediatesized lymphoma cells with round or slightly irregular nuclei and abundant pale or clear cytoplasm (Fig. 1D). Mitoses were infrequent. In all cases, the neoplastic cells were positive for CD45, CD3, and CD43. CD20 and CD79a stained scattered B cells, residual germinal center cells, and, in Case 1, subcapsular monocytoid B cells. The neoplastic T cells were negative for CD30, CD56, and ALK-1 in all cases in which staining was performed.

\section{Genotypic and Flow Cytometry Studies}

Results of ancillary studies are summarized in Table 4. T-cell receptor gene rearrangement studies were performed in six of eight cases. In all cases studied, monoclonal gene rearrangement of the T-cell receptor beta chain was demonstrated in the absence of immunoglobulin gene rearrangement. Three of eight cases had an aberrant population of CD4-positive $\mathrm{T}$ cells strongly expressing CD2 and CD5, with apparent deletion of CD3 and CD7 surface markers. Polytypic B cells were in the minority. In Case 3, no genotypic or flow cytometry studies were performed; however, this patient, who presented with generalized lymphadenopathy and involvement of the spleen by lymphoma, died of lymphoma 8 years after the initial diagnosis.

TABLE 2. Histologic Features in Lymph Node Biopsies

\begin{tabular}{cclll}
\hline Biopsy No. & Biopsy Site & \multicolumn{1}{c}{ Architectural Effacement } & \multicolumn{1}{c}{ Cytologic Features } & Inflammatory Infiltrate \\
\hline 1 & LN-C & partial with involvement of IF & $\begin{array}{l}\text { small to intermediate; slightly } \\
\text { irregular dark nuclei } \\
\text { small to intermediate; 1-3 nucleoli } \\
\text { small to intermediate; round to }\end{array}$ & $\begin{array}{l}\text { none } \\
\text { none } \\
\text { none }\end{array}$ \\
3 & LN-C & $\begin{array}{l}\text { diffuse } \\
\text { partial with compression of } \\
\text { GC, MZ pattern } \\
\text { partial with MZ pattern }\end{array}$ & $\begin{array}{l}\text { small to intermediate; round to } \\
\text { irregular nuclei }\end{array}$ & none \\
small monomorphic; round nuclei & many EOS; occasional \\
& LN-I & partial with expansion to IF & small to intermediate; round to & none \\
& LN-A & irregular nuclei & \\
\hline
\end{tabular}

LN-C, cervical lymph node; LN-I, inguinal lymph node; LN-A, axillary lymph node; LN-B, bile duct lymph node; GC, germinal center; MZ, marginal zone; IF, interfollicular zone; EOS, eosinophils; PLA, plasma cells. 
TABLE 3. Histologic Features in Extranodal Biopsies

\begin{tabular}{|c|c|c|c|c|}
\hline Biopsy No. & Biopsy Site & Architecture & Cytologic Features & Inflammatory Infiltrate \\
\hline 2 & submandibular gland & $\begin{array}{l}\text { diffuse } \\
\text { infiltrate }\end{array}$ & $\begin{array}{l}\text { small round cells; } \\
\text { round regular nuclei }\end{array}$ & none \\
\hline 3 & tonsil & $\begin{array}{l}\text { LEL; } \\
\text { residual GC; } \\
\text { MZ pattern }\end{array}$ & $\begin{array}{l}\text { small to intermediate; } \\
\text { round nuclei }\end{array}$ & none \\
\hline 4 & hard palate & LEL & $\begin{array}{l}\text { small to intermediate; } \\
\text { round nuclei }\end{array}$ & moderate EOS \\
\hline 6 & tongue & LEL & $\begin{array}{l}\text { small to intermediate; } \\
\text { round nuclei }\end{array}$ & none \\
\hline
\end{tabular}

LEL, lymphoepithelial lesion; GC, germinal center; MZ, marginal zone; EOS, eosinophils.

\section{DISCUSSION}

This study identifies eight cases of peripheral T-cell lymphoma mimicking marginal zone B-cell lymphoma on routine hematoxylin and eosinstained sections. Architecturally, there was an expansion of the marginal zone of follicles by small neoplastic cells with round or slightly irregular nuclei and abundant pale to clear cytoplasm, in some cases with expansion to the parafollicular compartment. Such partial effacement of the lymph node architecture is more characteristic of marginal zone lymphoma than of PTCL.

Extranodal sites of involvement included hard palate, tongue, tonsil, and submandibular glands. The extranodal lesions demonstrated some morphologic features considered typical for MALT lymphoma: lymphoepithelial lesions, germinal centers, marginal zone, and/or monocytoid B-cell morphology (9). The term lymphoepithelial lesion is widely used to describe the infiltration and destruction of

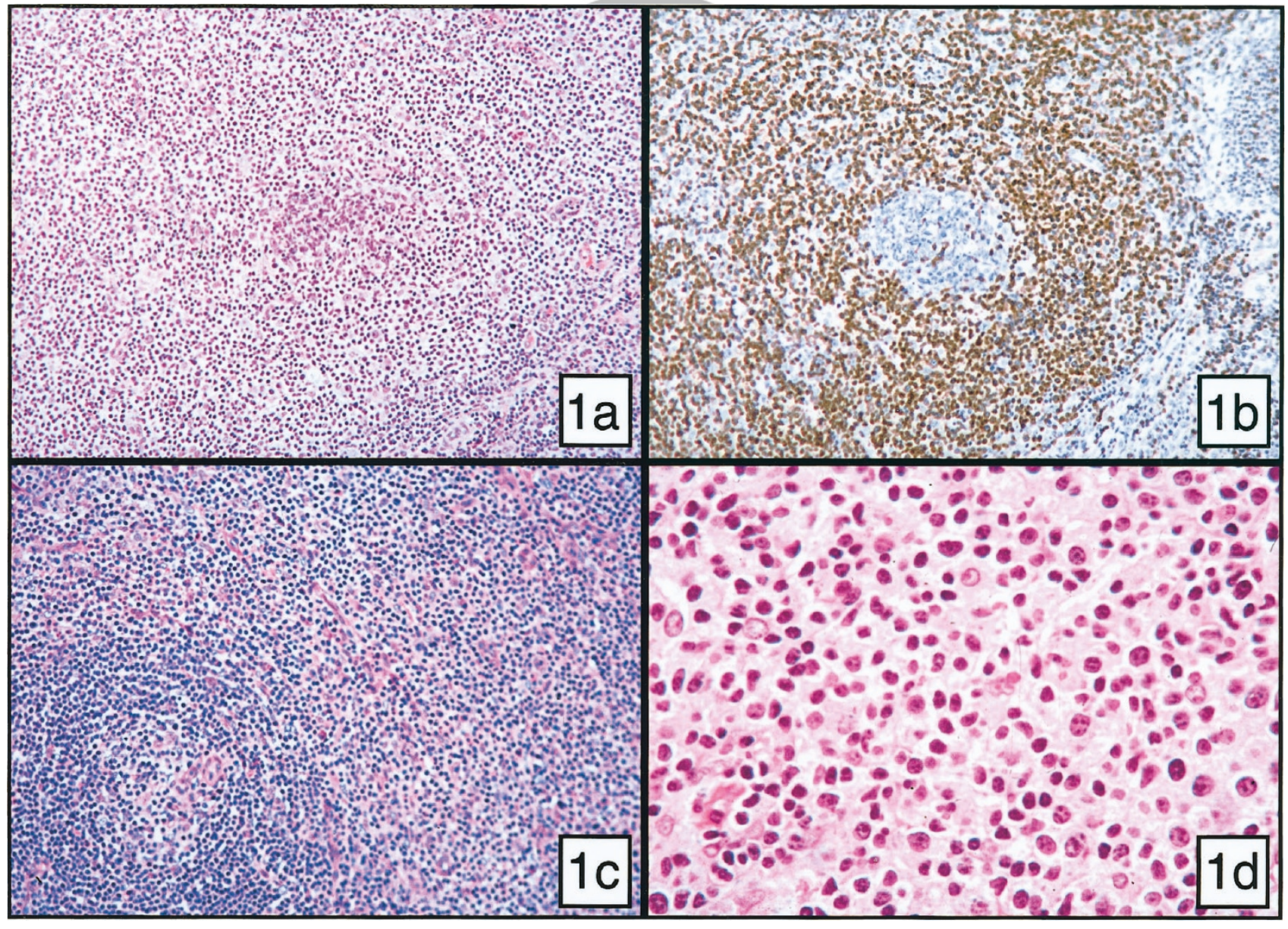

FIGURE 1. A representative lymph node biopsy. A, residual follicle with an expansion of the marginal zone (hematoxylin and eosin [H\&E], 100×) B, the neoplastic T-cells strongly express CD3 (immunohistochemical staining of CD3, 100×). C, expansion of marginal zone by small cells with abundant clear cytoplasm $(\mathrm{H} \& \mathrm{E}, 200 \times)$. D, the neoplastic infiltrate is composed of small cells with round or slightly irregular nuclei and abundant pale cytoplasm (H\&E, 400×). 


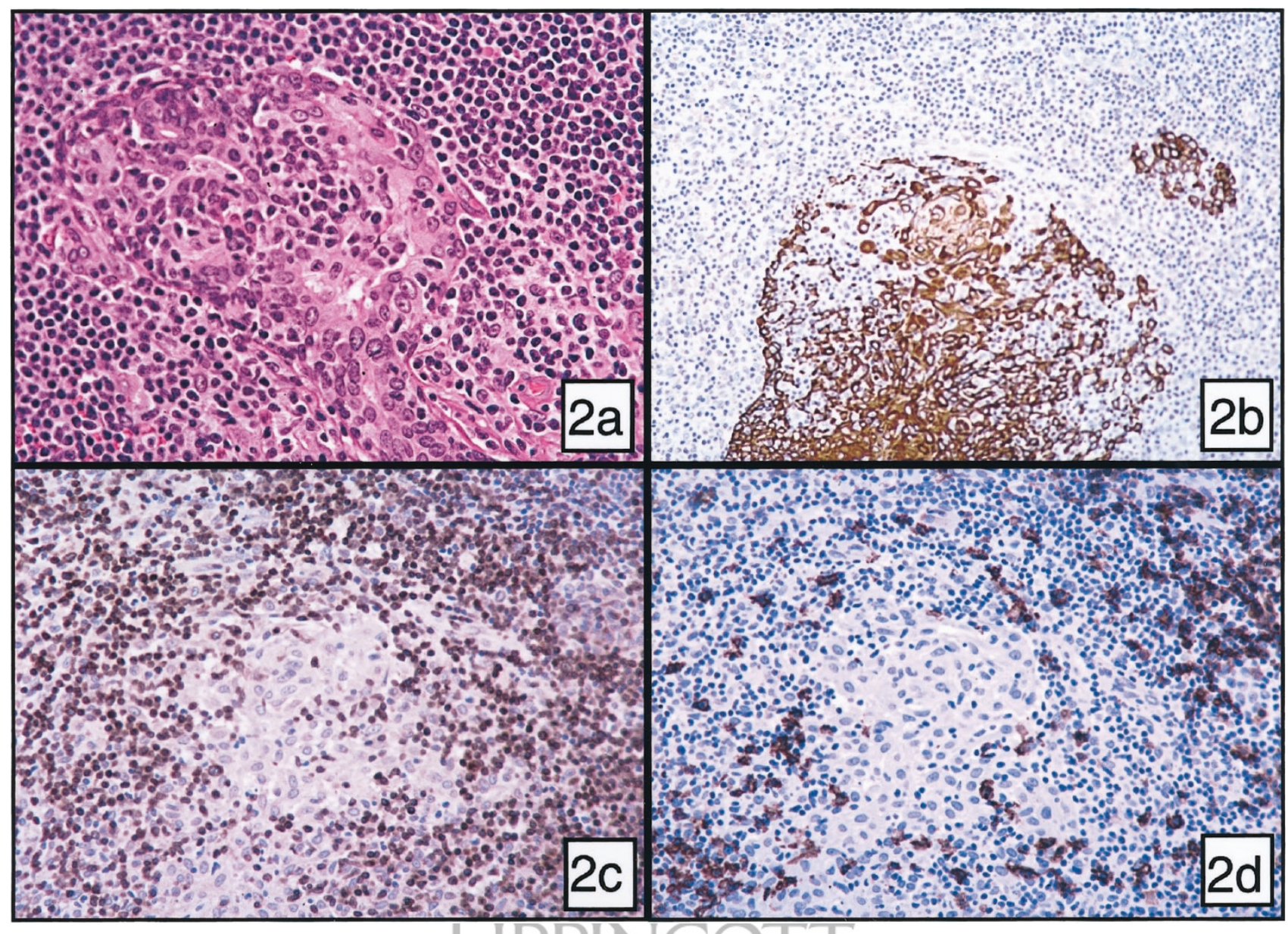

FIGURE 2. A representative extranodal site biopsy. A, lymphoepithelial lesion mimicking MALT lymphoma (hematoxylin and eosin, 200×). B, lymphoepithelial lesion highlighted by anti-cytokeratin (immunohistochemical staining of cytokeratin, $100 \times$ ). C, invasion and destruction of epithelial structures by the neoplastic T cells strongly expressing CD3 (immunohistochemical staining of CD3, 100×). D, lymphoepithelial lesion (immunohistochemical staining of CD20, 100×). Scattered nonneoplastic B cells express CD20.

TABLE 4. Genotypic and Flow Cytometry Study Results

\begin{tabular}{ccc}
\hline No. & TCR & Flow Cytometry \\
\hline 1 & + & ND \\
2 & ND & ${ }^{*}$ \\
3 & ND & $*$ \\
4 & + & $*$ \\
5 & + & ND \\
6 & + & ND \\
7 & + & ND \\
8 & + &
\end{tabular}

TCR, T-cell receptor gene rearrangement analysis; +, clonal T-cell population in the absence of B-cell clone; *, aberrant T-cell phenotype: $\mathrm{ND}$, not done.

epithelial structures produced by marginal zone and/or monocytoid B cells in MALT lymphoma (10). Lymphomas associated with lymphoepithelial lesions are usually MALT lymphomas; however, lymphoepithelial lesions have also been described in rare cases of T-cell and NK/T-cell lymphomas in the salivary glands (11).

Follicular colonization, commonly seen in nodal and extranodal marginal zone B-cell lymphomas, was not observed in our cases. In contrast, residual follicles appeared small and atrophic, with rare naked germinal centers. Many cases of marginal zone lymphoma also demonstrate plasma cell differentiation. Occasional plasma cells were present in only one of our cases. Thus, in assessing lymphoid lesions with a marginal zone pattern, the absence of follicular colonization and lack of plasmacytic differentiation raise a suspicion for PTCL. Immunohistochemistry is critical in resolving the differential diagnosis.

All but one of the presented cases were referred to our institution for consultation. Primary diagnoses entertained by referring or consulting pathologists in half of our cases included atypical reactive lesions and benign lymphoepithelial lesion. None of these cases was misdiagnosed as marginal zone B-cell lymphoma because of the immunohistochemical studies, which established the T-cell lineage of the lymphoid lesions. Gene rearrangement studies and/or flow cytometric analysis helped to establish clonality of these lesions.

Morphologic mimics of low grade B-cell lymphoma have been reported rarely in the literature 
(12-15). In fact, Rudiger and colleagues (13) first described nine cases of primary nodal PTCL with a distinct marginal zone pattern, occasionally with extension of lymphoma into the interfollicular T-zone. This pattern, seen also in our Cases 1 and 7, might be comparable to the T-zone lymphoma in the Kiel classification (4) or the T-zone variant of PTCL in the new World Health Organization classification (7). The T-zone variant typically shows an interfollicular growth pattern with small or medium-sized cells without pronounced nuclear pleomorphism. Differentiation from atypical T-zone hyperplasia may be impossible on morphological grounds and requires gene rearrangement studies for confirmation (7). However, the T-zone variant has been characterized by prominent high endothelial venules and numerous reactive cells, including plasma cells, eosinophils, and epithelioid histiocytes (7); these features were not prominent in our series.

Previously, Block and Banks (14) identified nine cases of T-cell lymphoma simulating MALT-type neoplasm in various extranodal sites. The case featuring the most striking mimicry presented as a gastric lesion with Helicobacter pylori gastritis and lymphoepithelial lesions. We did not identify such cases in the gastric mucosa; however, we noticed this striking resemblance in other mucosal sites, such as tongue, palate, and tonsils.

In summary, the peripheral T-cell lymphomas presented in this study have distinct morphologic features mimicking low grade B-cell lymphomas. Thus, the differential diagnosis of atypical lymphoid infiltrates with features of marginal zone B-cell lymphoma on conventional hematoxylin and eosin-stained sections should include PTCL. We recommend basic immunohistochemical studies for all cases with a marginal zone pattern. If differentiation from atypical T-cellhyperplasia is difficult based on morphologic and immunophenotypic findings, gene rearrangement studies should be performed to establish a definitive diagnosis of peripheral T-cell lymphoma. This uncommon morphological mimicry should be recognized because PTCL is an aggressive disease regardless of morphology and should be treated accordingly.

\section{REFERENCES}

1. Warnke RA, Weiss LM, Chan JCK, Cleary ML, Dorfman RF. Post-thymic T-cell lymphoma. In: Atlas of tumor pathology: tumors of the lymph nodes and spleen. 3rd series, Fascicle 14. Washington, D.C.: Armed Forces Institute of Pathology; 1995. p. 259-76.

2. Rappaport H. Tumors of the hematopoietic system. In: Atlas of tumor pathology, 1st series, Fascicle 8. Washington, D.C.: Armed Forces Institute of Pathology; 1966. p. 97-161.

3. The Non-Hodgkin's Lymphoma Pathologic Classification Project. National Cancer Institute sponsored study of classifications of non-Hodgkin's lymphomas: summary and description of a working formulation for clinical usage. Cancer 1982;49:2112-35.

4. Suchi T, Lennert K, Tu LY, Kikuchi M, Sato E, Stansfeld AG, et al. Histopathology and immunohistochemistry of peripheral T cell lymphomas: a proposal for their classification. J Clin Pathol 1987;40:995-1015.

5. Hastrup N, Hamilton-Dutoit S, Ralfkiaer E, Pallesen G. Peripheral T-cell lymphomas: an evaluation of reproducibility of the updated Kiel classification. Histopathology 1991;18: 99-105.

6. Harris NL, Jaffe ES, Stein H, Banks PM, Chan JK, Delsol G, et al. A revised European-American classification of lymphoid neoplasms: a proposal from the International Lymphoma Study Group. Blood 1994;84:1361-92.

7. Ralfkiaer E, Muller-Hermelink HK, Jaffe ES. Peripheral T-cell lymphoma, unspecified. In: World Health Organization classification of tumours: pathology and genetics of tumours of haematopoietic and lymphoid tissues. Lyon, France: IARC Press; 2001. p. 227-9.

8. Pinkus GS, Said JW. Peripheral T-cell lymphomas. In: Neoplastic hematopathology. 2nd ed. Philadelphia: Lippincott; 2001. p. 1091-125.

9. Harris NL, Isaacson PG. What are the criteria for distinguishing MALT from non-MALT lymphoma at extranodal sites? Am J Clin Pathol 1999;111:S126-32.

10. Isaacson $\mathrm{P}$, Wright $\mathrm{D}$. Malignant lymphoma of mucosaassociated lymphoid tissue. Histopathology 1987;11:445-62.

11. Chan JK, Tsang WY, Hui PK, Ng CS, Sin VC, Khan SM, et al. $\mathrm{T}$ - and T/natural killer-cell lymphomas of the salivary gland: a clinicopathologic, immunohistochemical and molecular study of six cases. Hum Pathol 1997;28:238-45.

12. Banks PM. Microscopic mimicry of lymphomas: diagnostic pitfalls. Mod Pathol 1999;12:116-24.

13. Rudiger T, Ichinohasama R, Ott MM, Muller-Deubert S, Miura I, Ott G, et al. Peripheral T-cell lymphoma with distinct perifollicular growth pattern: a distinct subtype of T-cell lymphoma? Am J Surg Pathol 2000;24:117-22.

14. Block JG, Banks PM. Mimicry of low-grade B-cell lymphoma of MALT type by other more aggressive lymphoma types. Mod Pathol 1999;12:132A.

15. Macon WR, Williams ME, Greer JP, Cousar JB. Paracortical nodular T-cell lymphoma. Identification of an unusual variant of peripheral T-cell lymphoma. Am J Surg Pathol 1995; 19:297-303. 